\title{
Influence of Freeze-Thaw Damage on the Steel Corrosion and Bond-Slip Behavior in the Reinforced Concrete
}

\author{
Fangzhi Zhu, ${ }^{1}$ Zhiming $\mathrm{Ma}^{2}{ }^{2}$ and Tiejun $\mathrm{Zhao}^{3}$ \\ ${ }^{1}$ School of Civil Engineering and Architecture, Suqian College, Suqian 223800, China \\ ${ }^{2}$ Department of Structural Engineering, Tongii University, Siping Road, Shanghai 200092, China \\ ${ }^{3}$ College of Civil Engineering, Qingdao University of Technology, Fushun Road, Qingdao 266033, China
}

Correspondence should be addressed to Fangzhi Zhu; fangzhi_zhu@163.com

Received 21 March 2016; Revised 19 June 2016; Accepted 11 July 2016

Academic Editor: Akihiko Kimura

Copyright (C) 2016 Fangzhi Zhu et al. This is an open access article distributed under the Creative Commons Attribution License, which permits unrestricted use, distribution, and reproduction in any medium, provided the original work is properly cited.

\begin{abstract}
This paper mainly studies the behavior of steel corrosion in various reinforced concrete under freeze-thaw environment. The influence of thickness of concrete cover is also discussed. Additionally, the bond-slip behavior of the reinforced concrete after suffering the freeze-thaw damage and steel corrosion has also be presented. The results show that the freeze-thaw damage aggravates the steel corrosion in concrete, and the results become more obvious in the concrete after suffering serious freeze-thaw damage. Compared with the ordinary concrete, both air entrained concrete and waterproofing concrete possess better resistance to steel corrosion under the same freeze-thaw environment. Moreover, increasing the thicknesses of concrete cover is also an effective method of improving the resistance to steel corrosion. The bond-slip behavior of reinforced concrete with corroded steel decreases with the increase of freeze-thaw damage, especially for the concrete that suffered high freeze-thaw cycles. Moreover, there exists a good correlation between the parameters of bond-slip and freeze-thaw cycles. The steel corrosion and bond-slip behavior of reinforced concrete should be considered serious under freeze-thaw cycles environment, which significantly impact the durability and safety of concrete structure.
\end{abstract}

\section{Introduction}

Concrete is a heterogeneous material with a high strength, and it also possesses a good versatility and relatively low cost, which makes concrete a man-made building material all over the world $[1,2]$. However, attributing to the unique composite materials that are porous and highly heterogeneous, the passageways are provided for the water and chloride penetrations into concrete, which reduce the concrete durability [35]. Under harsh environment especially, concrete durability rapidly decreases. As demand for concrete structures in harsh environment increases, the concern toward long service lives of reinforced concrete structures also increases [6]. Apart from the structure failure, the significant cause of deterioration is the durability problem. There are two main factors obviously affecting concrete durability among all. One main factor of durability deterioration is caused by freezing and thawing, and the freeze-thaw damage caused by the expansion stress in concrete is more serious under the coupling environment of freeze-thaw and saturated water $[7,8]$. The other main factor is the steel corrosion, and the chloride penetration is considered to be the primary cause of steel corrosion in reinforced concrete $[9,10]$. Steel corrosion in reinforced concrete produces corrosion products that are approximately two to six times greater in volume than the original steel, which induces expansive pressure on the surrounding concrete and eventually causes cracking of the concrete cover progressing toward the concrete surface [1115].

The steel is in a state of passivation in reinforced concrete when the interior of concrete is kept in a high alkaline environment ( $\mathrm{pH} 12.5-13.5$ ). However, the passivation environment is destroyed with chloride penetrating into concrete, and it leads to the steel corrosion after a series of electrochemical reactions. Under chloride environment especially, for example, marine environment, enough chlorides are 
TABLE 1: Mixture proportions of concrete, $\mathrm{Kg} / \mathrm{m}^{3}$.

\begin{tabular}{|c|c|c|c|c|c|c|c|}
\hline \multicolumn{2}{|c|}{ Specimen } & Cement & Sand & Gravel & Water & Air entrained agent & Silane gel \\
\hline \multirow{2}{*}{ Ordinary concrete } & C- 0.4 & 380 & 580 & 1270 & 152 & \multirow{4}{*}{$0.003 \%$} & \\
\hline & C-0.6 & 300 & 699 & 1191 & 180 & & \\
\hline Air entrained concrete & C-0.6A & 300 & 699 & 1191 & 180 & & \\
\hline Waterproofing concrete & C-0.6W & 300 & 699 & 1191 & 180 & & $400 \mathrm{~g} / \mathrm{m}^{3}$ \\
\hline
\end{tabular}

TABle 2: Primary properties of silane gel.

\begin{tabular}{lcccc}
\hline Product name & Place of origin & Concentration $\left(\mathrm{G} / \mathrm{cm}^{3}\right)$ & Character & Silane content \\
\hline StoCryl HG 200 $(\mathrm{HG})$ & EVONIK company in Germany & 0.96 & Gel & $75 \sim 100 \%$ \\
\hline
\end{tabular}

provided for penetration through the pores and cracks in concrete. In general, concrete cover provides a protection to prevent steel from corrosion, which reduces chloride penetration and provides a related stable environment for steel, but the protection decreases when reinforced concrete is subjected to the freeze-thaw environment. Concrete durability rapidly decreases with the increase of freeze-thaw damage, and more pores and cracks are formed, which provide passageways for chloride penetration; consequently, the steel corrosion risk significantly increases. Freeze-thaw environment and steel corrosion should be considered seriously for the durability and structural safety design.

Previous studies have investigated the steel corrosion in reinforced concrete in detail; however, most studies are carried out under common environment. Glass and Buenfeld give the presentation of the chloride threshold level for corrosion of steel in concrete [16]; Berrocal et al. present the corrosion of steel bars embedded in fibre reinforced concrete under chloride attack [17]; and Coccia et al. investigate the influence of corrosion on the bond strength of steel rebars in concrete [18]. Most researches on the steel corrosion in reinforced concrete almost neglect the influence of harsh environment, but the harsh environment frequently exists in the actual environment, such as freeze-thaw and chloride penetration environments. The service life of reinforced concrete structures usually is designed on the basis of one selected deteriorating mechanism, for instance, carbonation, chloride penetration, and frost action. However, those combined actions, such as chloride penetration in combination with freeze-thaw cycles, may shorten service life of reinforced concrete structures more than individual processes acting alone [19-23]. Consequently, taking the harsh environment and combined actions into consideration is important and necessary. From the sentences mentioned above, this paper is developed to investigate the steel corrosion and bond-slip behavior in reinforced concrete under the coupling effect of freeze-thaw damage and chloride penetration. The steel corrosion in various concrete under freeze-thaw environment is determined. Moreover, the bond-slip behavior between the concrete and the corrosion steel after suffering freeze-thaw cycles is also investigated, which has not been studied by the previous studies.

To achieve this objective, ordinary, air entrained, and waterproofing concrete were first prepared, and different freeze-thaw cycles were subsequently applied in concrete specimens. The status of steel corrosion in reinforced concrete was measured after suffering different freeze-thaw cycles, and the corrosion current density is used to evaluate the steel corrosion status. The influences of cover thicknesses and water cement ratio on steel corrosion under freezethaw environment are also discussed. For examining the accuracy of testing results of corrosion current density, the actual appearances of steel corrosion after different freezethaw cycles are also measured through a splitting test. Finally, the effects of freeze-thaw damage and corrosion of steel on the bond-slip behavior in reinforced concrete have also been investigated by bond-slip test, and it aims to evaluate the mechanical properties of reinforced concrete after suffering freeze-thaw damage and steel corrosion.

\section{Materials and Experimental Details}

2.1. Mixture Proportions and Concrete Specimens. Various concrete specimens are prepared first, and Table 1 shows the specific mixture proportions. Reinforced concrete specimen with the size of $280 \mathrm{~mm} \times 150 \mathrm{~mm} \times 75 \mathrm{~mm}$ can be seen from Figure 1. The influences of cover thickness and water cement ratio on steel corrosion in reinforced concrete under freezethaw environment are also discussed, and the cover thickness is, respectively, $15 \mathrm{~mm}$ and $30 \mathrm{~mm}$.

Air entrained concrete specimens are prepared to study the steel corrosion in air entrained concrete, and the incorporation of air entrained agent is $0.003 \%$ of the cement weighting. Table 2 gives the primary properties of silane gel used in preparing waterproofing concrete. Specimens were removed from the curing room after 28 days of curing, and the surfaces of part specimens were treated by silane gel to prepare waterproofing concrete. Subsequently, they were moved to the lab environment for 14 days to make sure that silane gel has penetrated into specimens. After that, all the specimens were subjected to the freeze-thaw cycles test.

2.2. Freeze-Thaw Cycles Test. The freeze-thaw cycles test was carried out according to the Standard Test Method for Resistance of Concrete to Rapid Freezing and Thawing (ASTM C666), and the size of concrete specimen used in freezethaw cycles test is $100 \mathrm{~mm} \times 100 \mathrm{~mm} \times 400 \mathrm{~mm}$. Because the waterproofing concrete possesses a good resistance to water 


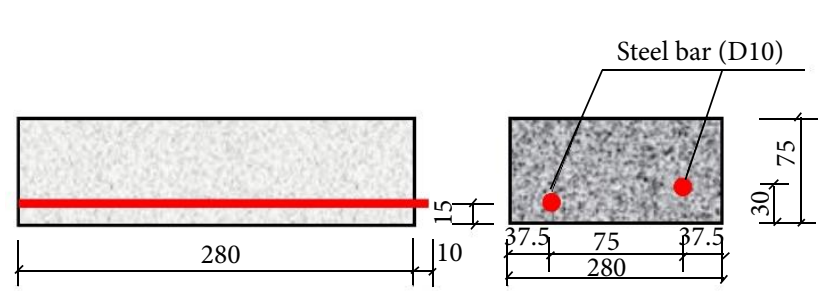

(a) Concrete specimen in accelerated steel corrosion test

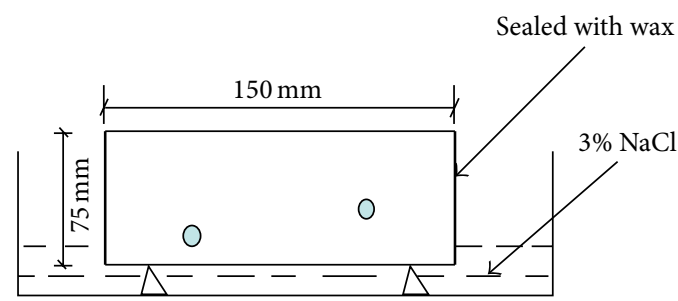

(b) Accelerated steel corrosion test

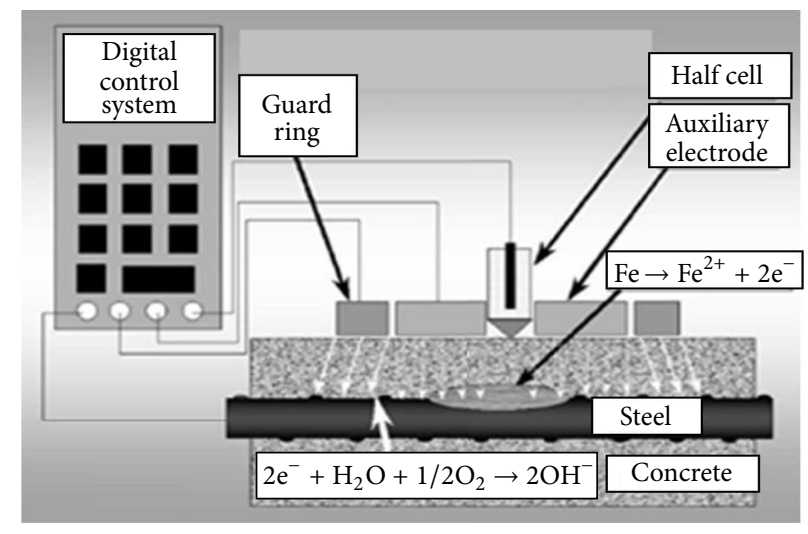

(c) Testing method of lineal polarization

FIGURE 1: Reinforced concrete specimen and the testing set-up of steel corrosion.

penetration, all specimens were stored in water for another 30 days; this aims to make the concrete in a water-saturated state. Eventually, all the specimens were put into the freeze-thaw equipment. One freeze-thaw cycle lasts about four hours, and the core temperature of the concrete ranges from $+8 \pm 2$ Celsius to $-17 \pm 2$ Celsius in one freeze-thaw cycle. After reaching a predefined number of freeze-thaw cycles, concrete specimens were taken out of the testing set-up, and relative dynamic modulus of elasticity was determined, which aims to evaluate the frost damage of concrete after different freezethaw cycles.

\subsection{Accelerated Steel Corrosion Test for Concrete Suffering the} Freeze-Thaw Damage. When the freeze-thaw cycles reach a predefined number $(N=0,10,50$, and 100 cycles), concrete specimens were taken out of the freeze-thaw set-up. Then, they were dried in a ventilated oven at $50^{\circ} \mathrm{C}$ until they reached constant weight, and four smaller side surfaces were sealed with wax to make the chloride penetrate into concrete in onedimensional way. The specimens were put into an aqueous salt solution containing $3 \% \mathrm{NaCl}$ to begin accelerated rebar corrosion test that lasted 200 days, and the testing set-up was shown in Figure 1(b). The current density $\left(I_{\text {corr }}\right)$ was measured in a predefined time, and steel corrosion rate can be estimated through the testing results of current density. After a 200-day test, the specimens were taken out of the salt solution and layers with a thickness of approximately $1 \mathrm{~mm}$ were milled successively starting from the exposed surface. Chloride content of the powder obtained in this way was determined by chemical analysis [24].
TABLE 3: Relation between corrosion current density and steel corrosion status.

\begin{tabular}{lc}
\hline Steel corrosion status & Corrosion current density \\
\hline Passivation status & $I_{\text {corr }}<0.1 \mu \mathrm{A} / \mathrm{cm}^{2}$ \\
Low to medium corrosion status & $I_{\text {corr }}=0.1-0.5 \mu \mathrm{A} / \mathrm{cm}^{2}$ \\
Medium to high corrosion status & $I_{\text {corr }}=0.5-1.0 \mu \mathrm{A} / \mathrm{cm}^{2}$ \\
Serious corrosion status & $I_{\text {corr }}>1.0 \mu \mathrm{A} / \mathrm{cm}^{2}$ \\
\hline
\end{tabular}

The steel corrosion rate in various reinforced concretes can be determined by the value of corrosion current density $I_{\text {corr }}$ according to the linear polarization principle. Figure 1(c) shows the method of lineal polarization to test steel corrosion in reinforced concrete $[25,26]$. Corrosion current density acts as the evaluation parameter of steel corrosion, and the calculation formula of corrosion current density is given in (1). Combining with the Standard Test Method for Determining Effects of Chemical Admixtures on Corrosion of Embedded Steel Reinforcement in Concrete Exposed to Chloride Environments (ASTM G109-2007), Table 3 gives the relation between corrosion current density and steel corrosion status. When $I_{\text {corr }}>0.1 \mu \mathrm{A} / \mathrm{cm}^{2}$, the steel is considered to be corroding $[26,27]$. Steel corrosion rate increases with the increase of the value of corrosion current density. Consider

$$
\begin{aligned}
I_{\text {corr }}=\frac{b_{a} b_{c}}{2.303\left(b_{a}+b_{c}\right)} \cdot \frac{1}{R_{\rho}}=\frac{B}{R_{\rho}}, & \\
B & =\frac{b_{a} b_{c}}{2.303\left(b_{a}+b_{c}\right)},
\end{aligned}
$$




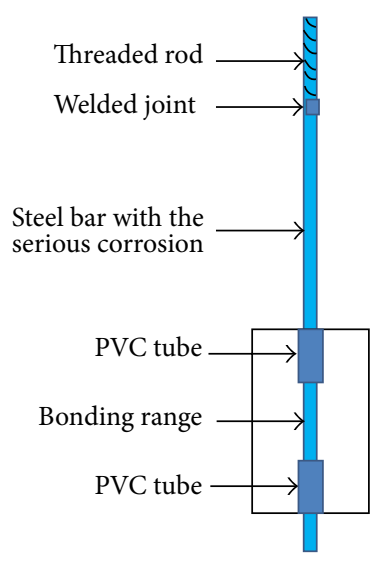

(a) Without loading

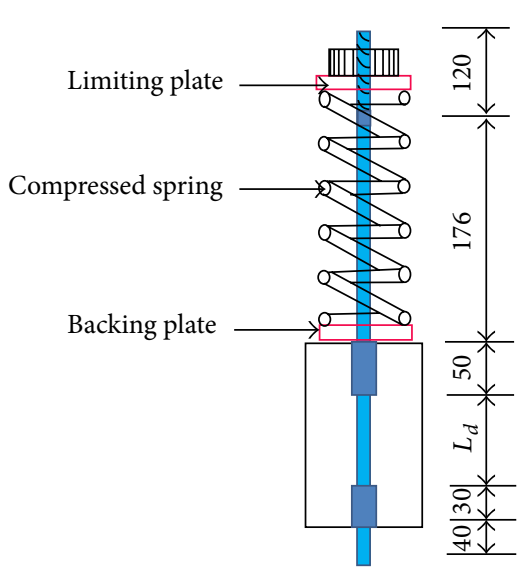

(b) With sustaining load

FIGURE 2: Bond-slip testing set-up for the concrete suffering the coupling effect of freeze-thaw damage and steel corrosion.

TABLE 4: Relative dynamic modulus of elasticity of concrete after different freeze-thaw cycles.

\begin{tabular}{lcccc}
\hline \multirow{2}{*}{ Freeze-thaw cycles $(N)$} & \multicolumn{4}{c}{ Specimens } \\
& C-0.4 & C-0.6 & C-0.6A & C-0.6W \\
\hline 0 & 100 & 100 & 100 & 100 \\
10 & 98.8 & 89.8 & 97.7 & 97.2 \\
25 & 96.3 & 76.1 & 96.5 & 96 \\
50 & 91.2 & 55 & 95.5 & 93 \\
100 & 76 & 20 & 95.2 & 53 \\
\hline
\end{tabular}

where $I$ is polarization current, $I_{\text {corr }}$ is corrosion current density, $\eta$ is over potential, $R_{\rho}$ is polarization resistance, and $b_{a}$ and $b_{c}$ are the Tafel constants of the negative and positive poles.

2.4. Bond-Slip Test for Concrete Suffering the Coupling Action of Freeze-Thaw Damage and Steel Corrosion. The bond-slip test of various reinforced concrete after suffering the coupling action of freeze-thaw damage and steel corrosion was also carried out, as shown in Figure 2. Additionally, the corrosion current densities of the steel in reinforced concrete specimens in the bond-slip test are all above $1.0 \mu \mathrm{A} / \mathrm{cm}^{2}$, and it demonstrates that the steel is in a state of serious corrosion. Two kinds of loading states were applied in the specimens, respectively, including with sustaining load and without loading. The length of $L_{d}$ is about 7 times as high as the bar diameter, and the bar diameter is $12 \mathrm{~mm}$. The concrete specimens with serious steel corrosion were first prepared, and then different freeze-thaw cycles were applied to the specimens. When the freeze-thaw cycles reached 0,25 , and 50 cycles, the bond-slip test was subsequently carried out, and the provided loadings were $0 \%, 30 \%$, and $50 \%$ of ultimate pulling strength, respectively.

\section{Results and Discussion}

3.1. Frost Resistance for Different Concrete. Table 4 shows relative dynamic modulus of elasticity of concrete after suffering different freeze-thaw cycles. The results show relative dynamic modulus of elasticity decreases with the increase of freeze-thaw cycles. The freeze-thaw cycles have a significant impact on relative dynamic modulus of elasticity of concrete specimens. When the freeze-thaw cycles reach 100 times, relative dynamic modulus of elasticity of C-0.4, C0.6, C-0.6A, and C-0.6W specimens, respectively, decreases by $24 \%, 80 \%$, $4.8 \%$, and $47 \%$ compared with that after zero freeze-thaw cycles. The frost resistance decreases with the increase of water cement ratio, and the influences are very obvious. For various concrete specimens with the same water cement ratio, ordinary concrete has the lower relative dynamic modulus compared with air entrained and waterproofing concrete after suffering the same freeze-thaw cycles, which shows that ordinary concrete has an inferior frost resistance.

C-0.6A specimen has a superior frost resistance, even after suffering high freeze-thaw cycles. This can be attributed to the addition of air entrained agent, and emerged independent and closed pore structures in C-0.6A concrete improve the frost resistance. Independent pore structures can well relieve the internal expansion pressure in concrete under freeze-thaw environment. However, the pores in ordinary concrete are most connected, which play an adverse effect on the frost resistance under freeze-thaw environment. C-0.6W specimen also has a better frost resistance compared with ordinary concrete under the same freeze-thaw environment, which is due to the existence of hydrophobic coating on the surface of waterproofing concrete. The hydrophobic coating is formed after a series of chemical reactions, and then the water penetration is reduced. Consequently, the frost damage caused by the freezing and thawing expansion stress is subsequently decreased, and the frost resistance is improved. 

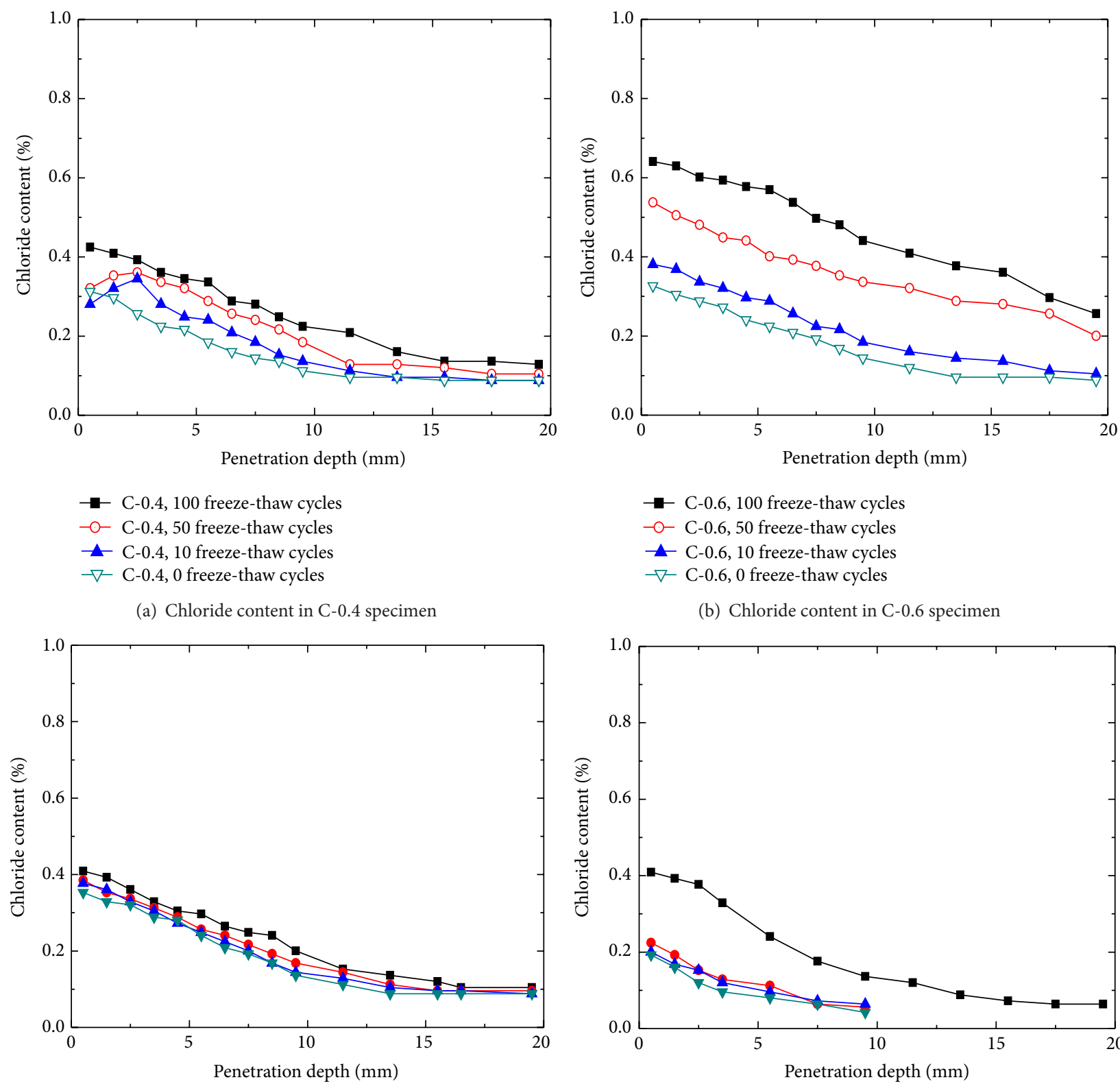

(b) Chloride content in C-0.6 specimen

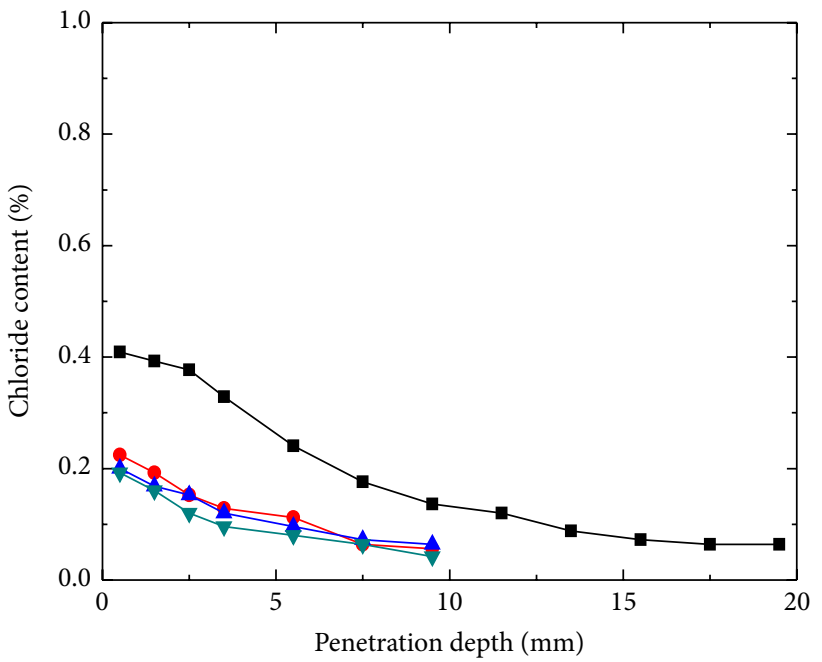

C-0.6A, 100 freeze-thaw cycles

$-0-\mathrm{C}-0.6 \mathrm{~A}, 50$ freeze-thaw cycles

- C-0.6A, 10 freeze-thaw cycles

$\nabla$ C-0.6A, 0 freeze-thaw cycles

(c) Chloride content in C-0.6A specimen

FIGURE 3: Chloride content in different concrete.

3.2. Chloride Content Determined for Various Concrete after Different Freeze-Thaw Cycles. As is well known, chloride penetration is the major cause of steel corrosion in reinforced concrete. Chloride contents in various concrete are determined after suffering different freeze-thaw cycles, and the chloride content curves are shown in Figure 3. As shown in Figures 3(a) and 3(b), the maximum chloride content increases with the increase of water cement ratio after suffering the same freeze-thaw cycles, and the increasing of chloride content becomes more obvious after high freezethaw cycles. Comparing with the results of Figure 3(b), Figures 3(c), and 3(d), chloride content in C-0.6 specimen is higher than that of $\mathrm{C}-0.6 \mathrm{~A}$ and $\mathrm{C}-0.6 \mathrm{~W}$ specimens after suffering the same freeze-thaw cycles. When the freeze-thaw cycles are zero, the maximum chloride content of C-0.6, C$0.6 \mathrm{~A}$, and C-0.6W specimens is, respectively, $0.34 \%, 0.35 \%$, and $0.2 \%$, and the results become $0.65 \%, 0.41 \%$, and $0.42 \%$ after 100 freeze-thaw cycles. The maximum chloride content 


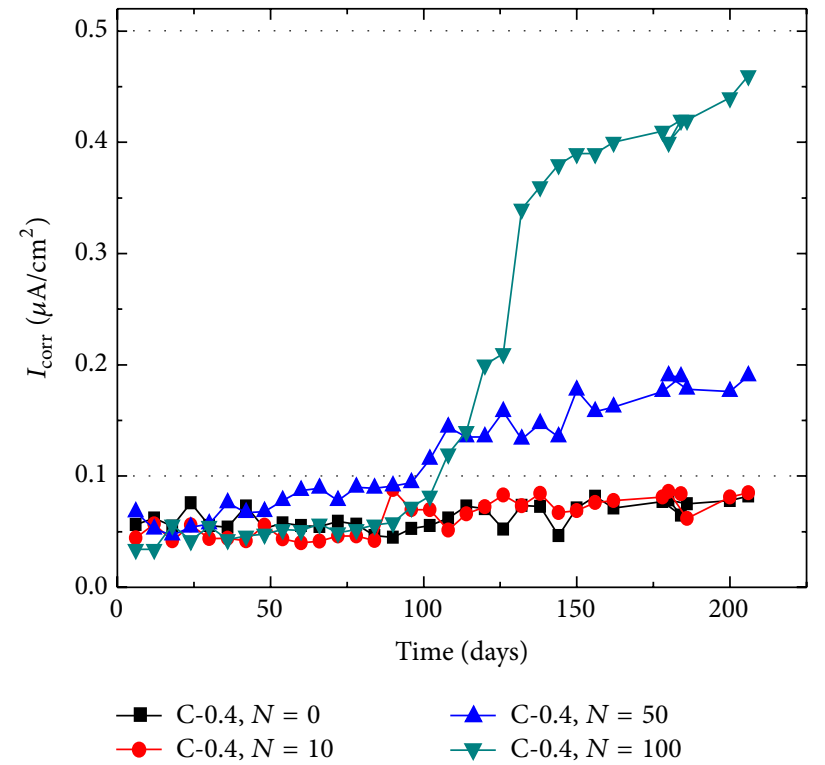

(a) Water cement ratio is 0.4

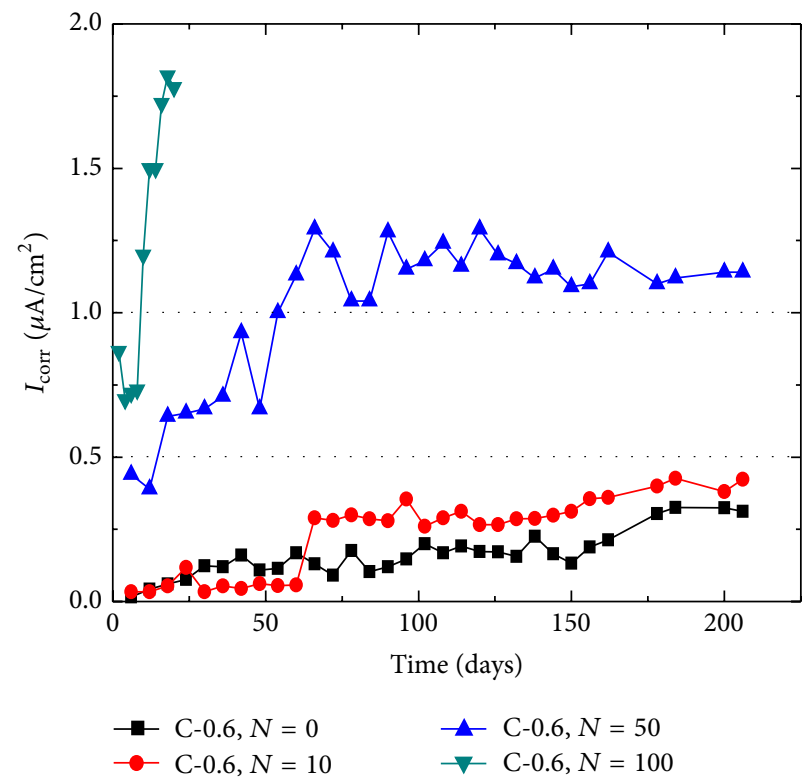

(b) Water cement ratio is 0.6

FIGURE 4: Corrosion current density in ordinary concrete when cover thickness is $15 \mathrm{~mm}$.

is concluded to increase with the increase of freeze-thaw cycles. Additionally, air entrained concrete and waterproofing concrete have a better resistance to chloride penetration compared with ordinary concrete under the same freezethaw environment.

The reason is that the freeze-thaw cycles aggravate the concrete damage, and more cracks and pores are formed in concrete. Water and chloride penetrate into concrete mainly through the cracks and pores; consequently, more passageways are provided for the chloride penetration with the frost damage increasing. C-0.6A specimen possesses a better frost resistance than C- 0.6 specimen, and the chloride content of C-0.6A specimen is much lower than that of C- 0.6 specimen under the same freeze-thaw environment. The C$0.6 \mathrm{~W}$ specimen has a better resistance to water penetration, and the chloride penetrates into concrete mainly by the medium of water. Consequently, the chloride content is also reduced, and the chloride content of C- $0.6 \mathrm{~A}$ and C- $0.6 \mathrm{~W}$ is lower than that of C- 0.6 specimen even after high freeze-thaw cycles.

\subsection{Steel Corrosion Behavior for Various Reinforced Concrete after Different Freeze-Thaw Cycles}

3.3.1. Steel Corrosion Behavior for Fresh Concrete after Different Freeze-Thaw Cycles. Figure 4 shows the testing results of corrosion current density in reinforced concrete with $15 \mathrm{~mm}$ concrete thickness. The results demonstrate that the freezethaw cycles have a significant impact on corrosion current density, and the corrosion current density increases with the increasing of freeze-thaw cycles and testing time. Comparing with the results in Figures 4(a) and 4(b), corrosion current density increases with the increased water cement ratio. For C-0.4 specimen, after 200-day accelerated corrosion, the corrosion current density after $0,10,50$, and 100 freeze-thaw cycles is, respectively, $0.082,0,085,0.19$, and $0.46 \mu \mathrm{A} / \mathrm{cm}^{2}$, as shown in Figure 4(a); and the results become 0.31, 0.42, 1.14 , and $1.78 \mu \mathrm{A} / \mathrm{cm}^{2}$ for C-0.6 specimen after 200-day accelerated corrosion, as shown in Figure 4(b). The influence of water cement ratio on corrosion current density is obvious, and the changing becomes more obvious after high freezethaw cycles.

Combing with the relation between corrosion current density and steel corrosion status, as shown in Table 3, the steel corrosion status can be measured. When the accelerated steel corrosion test reaches 200 days, the steel in C- 0.4 specimen is at the state of passivation after zero freeze-thaw cycles, and the steel is at the state of medium to high corrosion after 100 freeze-thaw cycles. The steel in C- 0.6 is at the state of low to medium corrosion after zero freeze-thaw cycles, and steel is at the state of serious corrosion after 100 freeze-thaw cycles. It is remarkable that the frost increases the steel corrosion rate. Frost damage aggravates the concrete degradation. More cracks and pores are formed after suffering frost damage, and the protection provided by concrete is decreased [2830]. More passageways are provided for chloride penetration under the environment exposed to the chloride penetration, and they increase the steel corrosion rate. Consequently, the steel corrosion rate rapidly increases with the increase of freeze-thaw cycles. Decreasing water cement ratio is an effective method to reduce the steel corrosion rate under freeze-thaw environment. The actual appearance of steel corrosion in ordinary concrete after different freeze-thaw cycles was also measured through a splitting test, and it aims to evaluate the testing accuracy of corrosion current density. The actual steel corrosion in C-0.6 specimen is with a little rust when the freeze-thaw cycles are zero, and the actual steel corrosion is with mass rust after 100 freeze-thaw cycles. 


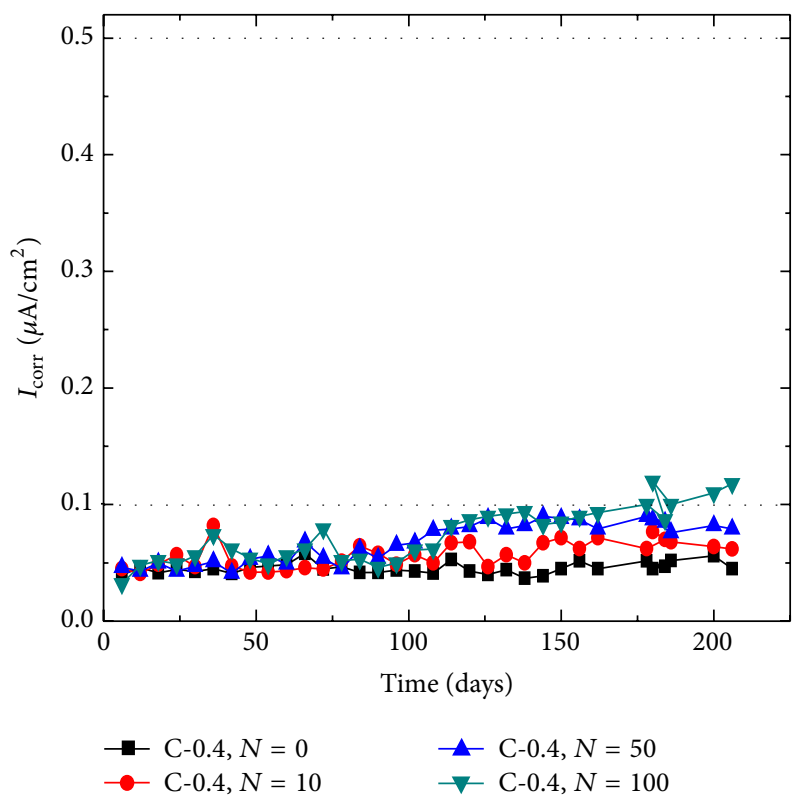

(a) Water cement ratio is 0.4

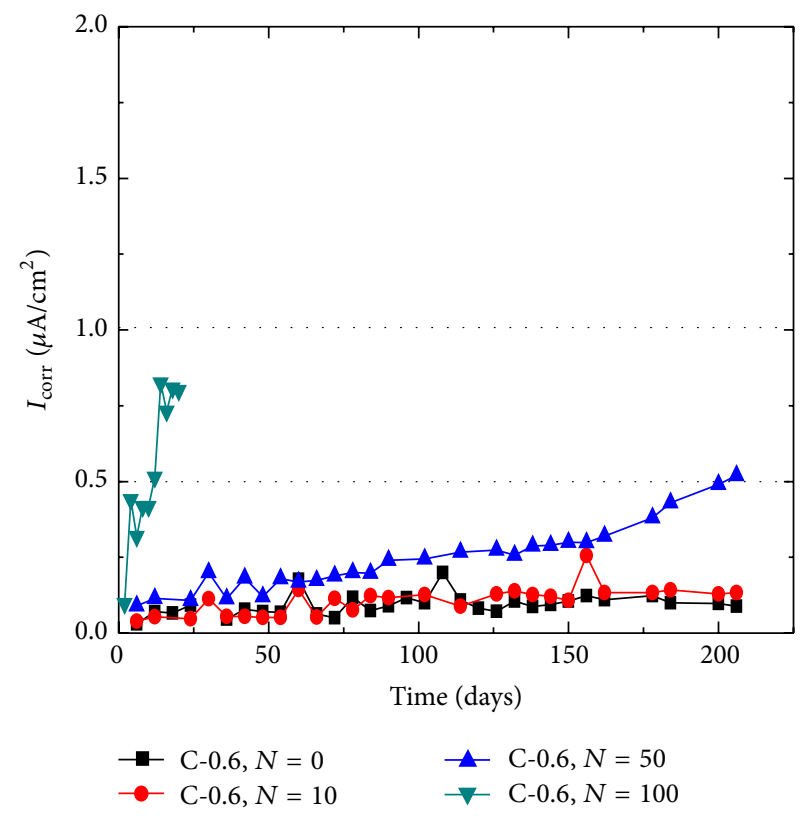

(b) Water cement ratio is 0.6

FIGURE 5: Corrosion current density in ordinary concrete when cover thickness is $30 \mathrm{~mm}$.

Comparing with the testing results of corrosion current density, it is obvious that there exists a good correlation between the testing results and the actual steel corrosion status.

For investigating the influence of cover thickness on steel corrosion under freeze-thaw environment, Figure 5 gives the testing results of corrosion current density with $30 \mathrm{~mm}$ cover thickness. Comparing with the results in Figures 4 and 5, it turns out that the corrosion current density significantly decreases with the increase of cover thickness for the same concrete after suffering the same freeze-thaw cycles. Chloride content decreases with the increase of penetration depth, and the protection of steel is provided by the cover thickness. As a consequence, increasing cover thickness is another effective method to reduce steel corrosion rate under freeze-thaw environment.

3.3.2. Steel Corrosion Behavior of Air Entrained Concrete after Different Freeze-Thaw Cycles. Air entrained concrete possesses a good frost resistance, and it is frequently applied in the construction under frost environment. This section is developed to investigate the steel corrosion in air entrained concrete under freeze-thaw environment. Figure 6 shows the testing results of corrosion current density in C-0.6A specimen. The results show freeze-thaw cycles and cover thickness have a significant impact on the steel corrosion under freeze-thaw environment. When concrete cover is $15 \mathrm{~mm}$ and the corrosion time reaches 200 days, corrosion current densities after different freeze-thaw cycles all range from 0.1 to $0.5 \mu \mathrm{A} / \mathrm{cm}^{2}$, which shows the steel is at the state of low to medium corrosion, combined with Table 3 . When the concrete cover is $30 \mathrm{~mm}$ and the corrosion time reaches 200 days, the corrosion current densities after 0,10 , and 50 freeze-thaw cycles are all below $0.1 \mu \mathrm{A} / \mathrm{cm}^{2}$, and it shows the steel is at the state of passivation; moreover, there is no rust on the steel surface. The value becomes $0.15 \mu \mathrm{A} / \mathrm{cm}^{2}$ when the freeze-thaw cycles are 100 times, and steel is at the state of low to medium corrosion, which demonstrates the rust is formed on the steel surface. Comparing with the results in Figures 4, 5 , and 6 , corrosion current density in air entrained concrete is much lower than that in ordinary concrete under the same condition, which shows steel in air entrained concrete has a lower corrosion rate. Additionally, the steel is pulled out of concrete after 200 days of accelerated corrosion, and the results show that there exists a good correlation between the actual steel corrosion and the testing results of corrosion current density.

Attributing to the addition of air entraining agent, unique pore structures are formed, which improve the frost resistance of air entrained concrete. Figure 7 gives the image of pore structure in fresh concrete and air entrained concrete through the set-up of Scanning Electron Microscope (SEM). Independent and closed pore structures can be seen in the air entrained concrete, and they can well relieve the internal expansion pressure caused by the freezing and thawing damage; consequently, the frost damage in air entrained concrete is much lower than that in fresh concrete. Even after high freeze-thaw cycles, the steel is also at the state of low corrosion rate, and the actual rebar corrosion also approves the testing results of corrosion current density. As mentioned above, the conclusion is drawn that air entrained concrete has a better resistance to rebar corrosion than ordinary concrete under freeze-thaw environment.

3.3.3. Steel Corrosion Behavior for Waterproofing Concrete after Different Freeze-Thaw Cycles. Attributing to the good 


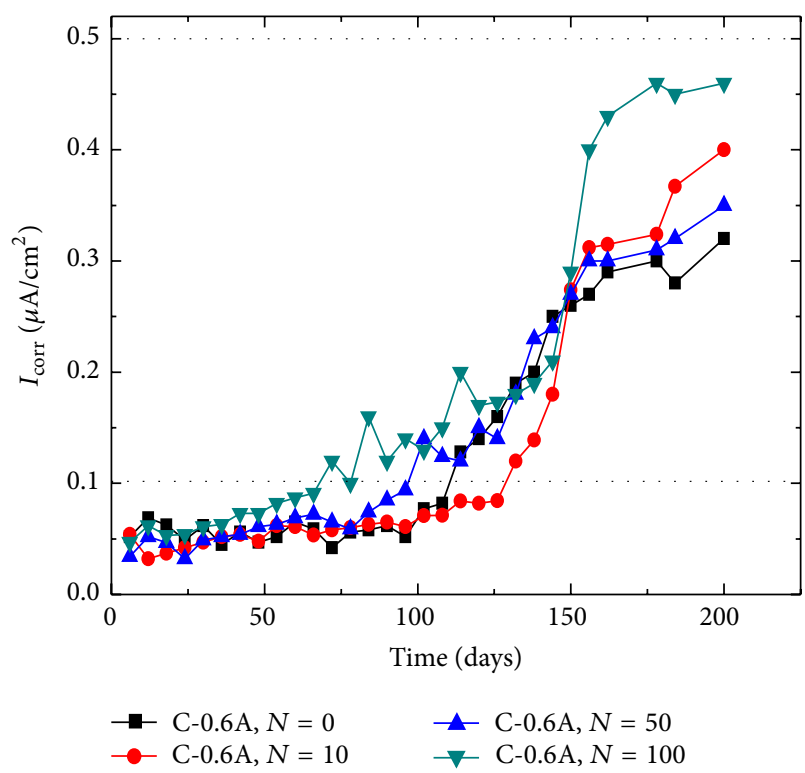

(a) Cover thickness is $15 \mathrm{~mm}$

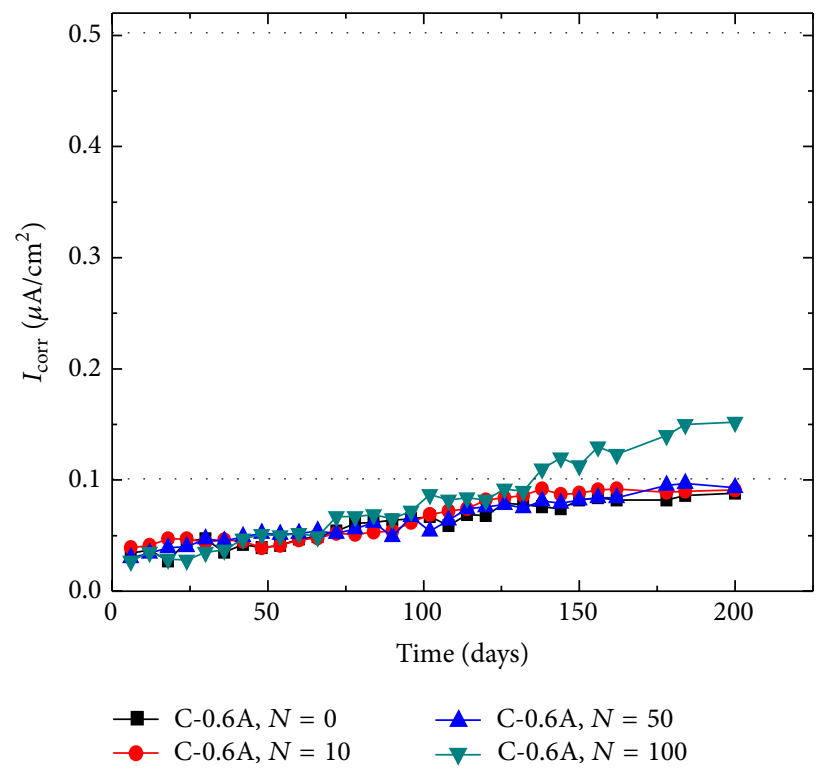

(b) Cover thickness is $30 \mathrm{~mm}$

Figure 6: Corrosion current density in C-0.6A specimen with different cover thicknesses.

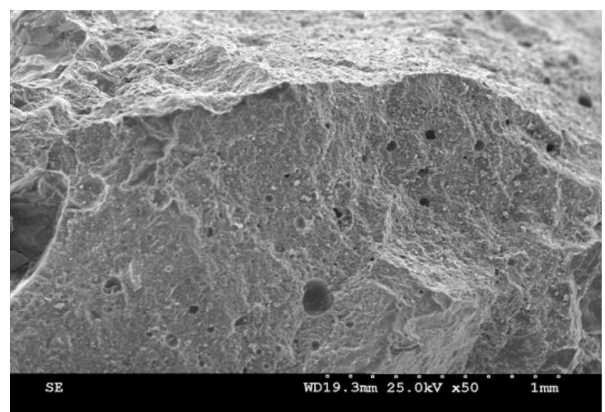

(a) Fresh concrete

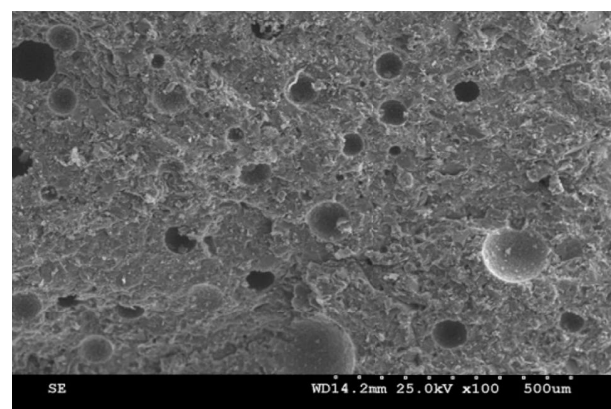

(b) Air entrained concrete

Figure 7: Pore structures in fresh concrete and air entrained concrete.

resistance to the water and chloride penetrations, the durability of waterproofing concrete is improved, and waterproofing concrete has been applied in the harsh environment, on a large scale. This section aims to test the steel corrosion in waterproofing concrete under freeze-thaw environment, and the influence of cover thickness on steel corrosion is also discussed. Figure 8 shows the testing results of corrosion current density in C-0.6W specimens. In general, the value of corrosion current density increases with the increase of freeze-thaw cycles and corrosion time. As shown in Figure $8(\mathrm{a})$, when the time of accelerated steel corrosion reaches 200 days, the corrosion current densities are all below $0.1 \mu \mathrm{A} / \mathrm{cm}^{2}$ after 0,10 , and 50 freeze-thaw cycles, which indicates that the steel is at the state of passivation. The value becomes $0.2 \mu \mathrm{A} / \mathrm{cm}^{2}$ after 100 freeze-thaw cycles, and it demonstrates the steel is at the state of low to medium corrosion. Additionally, the actual steel has no rust in C$0.6 \mathrm{~W}$ specimen after zero freeze-thaw cycles, and the steel is with a little rust in C-0.6W specimen after 100 freezethaw cycles through a splitting test. Although the results show that frost damage increases the steel corrosion rate, the steel corrosion rate in waterproofing concrete is lower than that in ordinary concrete under the same freeze-thaw environment. Even after high freeze-thaw cycles, steel corrosion rate in waterproofing concrete is also reduced. Comparing with the results in Figures 8(a) and 8(b), the steel corrosion rate reduces with the increase of cover thickness.

A series of chemical reactions existed in waterproofing concrete in the processing of forming a hydrophobic coating. When the silane gel contacts with concrete, it rapidly penetrates into concrete under the action of capillary absorption. Alkyl alkoxy silane first reacts with water, and the silanol is produced. Subsequently, the silanol reacts with the concrete. Eventually, a hydrophobic coating is produced on the surface of the concrete through a condensation reaction of the active group. The surface tension of the capillary channel in concrete 


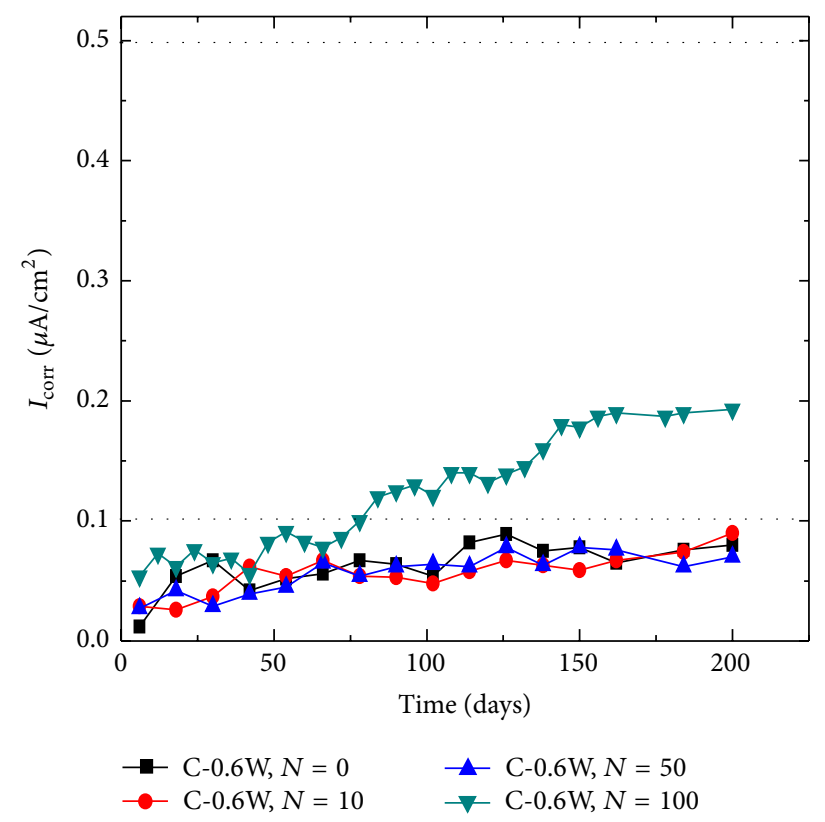

(a) Cover thickness is $15 \mathrm{~mm}$

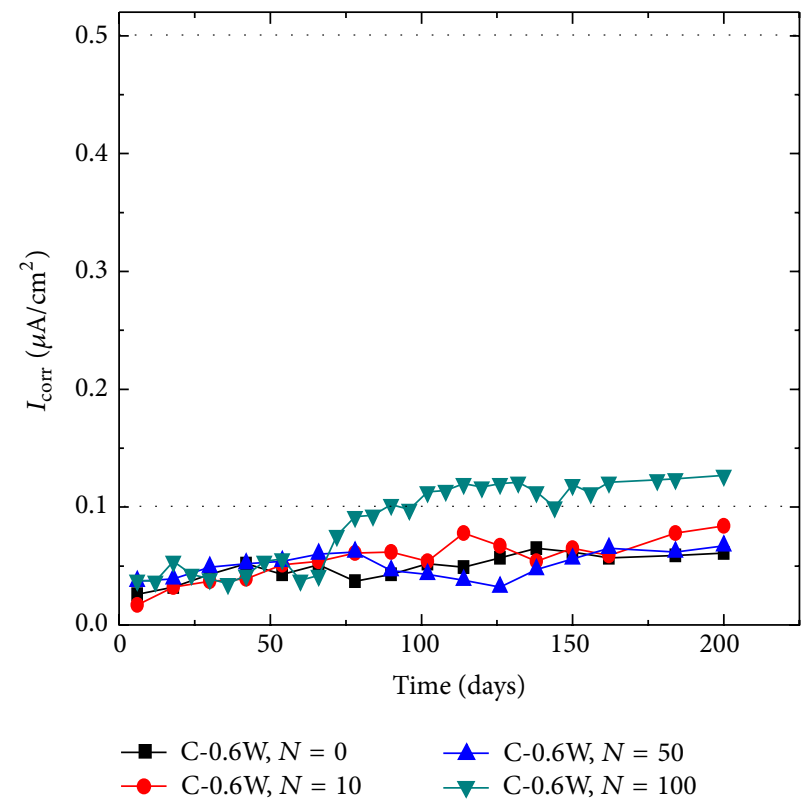

(b) Cover thickness is $30 \mathrm{~mm}$

FIGURE 8: Corrosion current density in C-0.6W specimen with different cover thicknesses.

is thus decreased, and the water penetration is effectively reduced. The steel corrosion is mainly caused by the chloride penetration, and the transmission of chloride penetration is mainly by the water penetration. Consequently, the chloride penetration reduces with the decrease of water penetration in waterproofing concrete, and the steel corrosion rate also reduces.

\subsection{Bond-Slip Behavior for Reinforced Concrete Suffering the} Coupling Action of Freeze-Thaw Damage and Steel Corrosion. The bond-slip behavior is the main evaluation indicator for the structure safety of reinforced concrete. This section aims to investigate the bond-slip behavior of reinforced concrete with serious corrosion of steel after suffering different freezethaw cycles, and the results are shown in Figure 9. It is obvious that the freeze-thaw cycles have a significant impact on the bond-slip behavior of reinforced concrete, and the maximum pull-out load decreases with the increase of freezethaw cycles. As shown in Figure 9(b), the influence of applied sustaining load on the bond-slip behavior of reinforced concrete is not obvious when the freeze-thaw cycles are below 25 times. However, the effect of applied sustaining load on the bond-slip behavior of reinforced concrete becomes more obvious when the freeze-thaw cycles reach 50 cycles, as shown in Figure 9(c). The maximum pull-out loads for concrete applied $30 \%$ and $50 \%$ of ultimate pulling strength decrease by $22.8 \%$ and $48.5 \%$, respectively. The high freezethaw cycles and serious frost damage increase the deterioration rate of the bond-slip behavior in reinforced concrete, and the deterioration rate of the bond-slip behavior also increases with the increase of applied sustaining load. Figure 10 gives the relationship between the ultimate bond strength, slip peak, and freeze-thaw cycles, and it shows that there exists a good correlation between the ultimate bond strength and freeze-thaw cycles; moreover, there also exists a good correlation between the slip and freeze-thaw cycles, which provides a method to evaluate the bond-slip behavior of reinforced concrete under freeze-thaw cycles, approximately. Especially for the reinforced concrete after suffering a serious frost damage, the bond-slip behavior of reinforced concrete should be considered seriously. Additionally, the relationship between the freeze-thaw tests in laboratory and field exposure has been established according to Li et al. [31]. Although, the relationship obtained in this paper cannot be directly used to evaluate the bond-slip behavior of reinforced concrete under actual environment, it provides some important factors for the designing of durability performance and structure safety of reinforced concrete, approximately.

\section{Conclusion}

This paper is developed to study the steel corrosion in various concrete under freeze-thaw environment. Ordinary concrete, air entrained concrete, and waterproofing concrete are prepared. Based on the results of this experimental work presented above, the following conclusions are drawn:

(1) Relative dynamic modulus of elasticity decreases with the increase of freeze-thaw cycles, and the chloride content increases with the increase of freeze-thaw cycles. Freeze-thaw cycles significantly influence the steel corrosion in ordinary concrete, and frost damage increases the steel corrosion rate. Especially after high freeze-thaw cycles, serious steel corrosion happened. Increasing the cover thicknesses and decreasing the water cement ratio are two effective methods to 


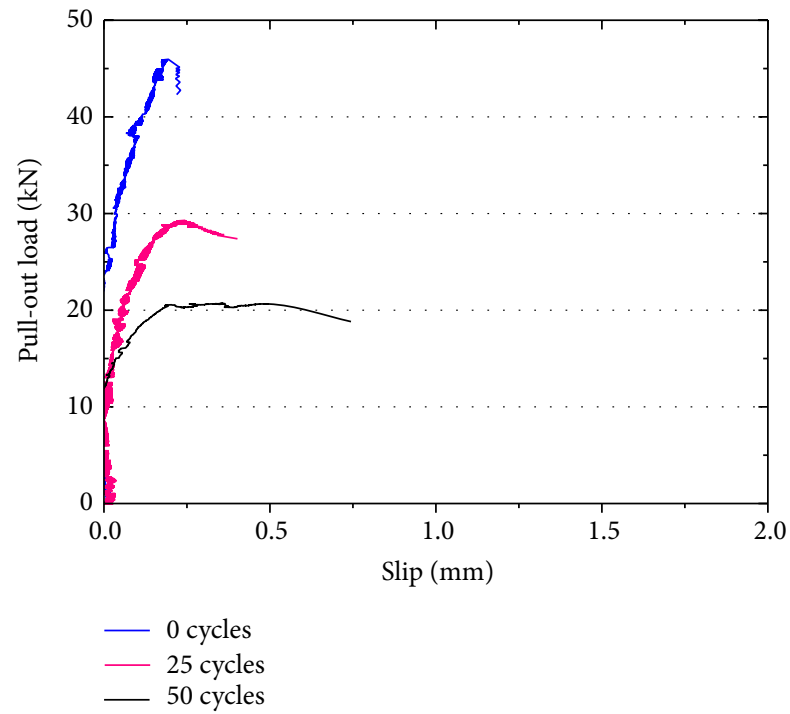

(a) Different freeze-thaw cycles and without applied sustaining load

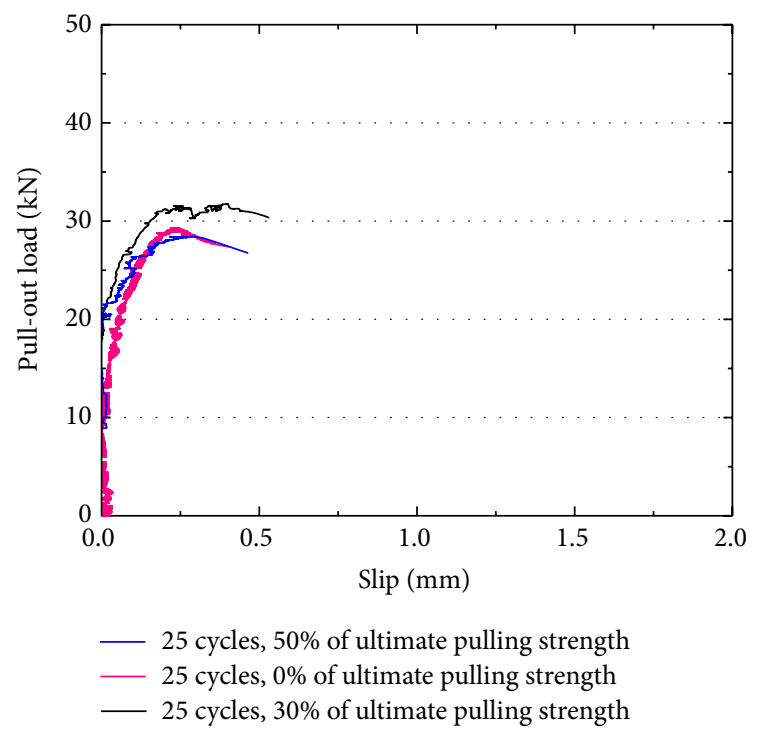

(b) Freeze-thaw cycles are 25 times and with applied sustaining load

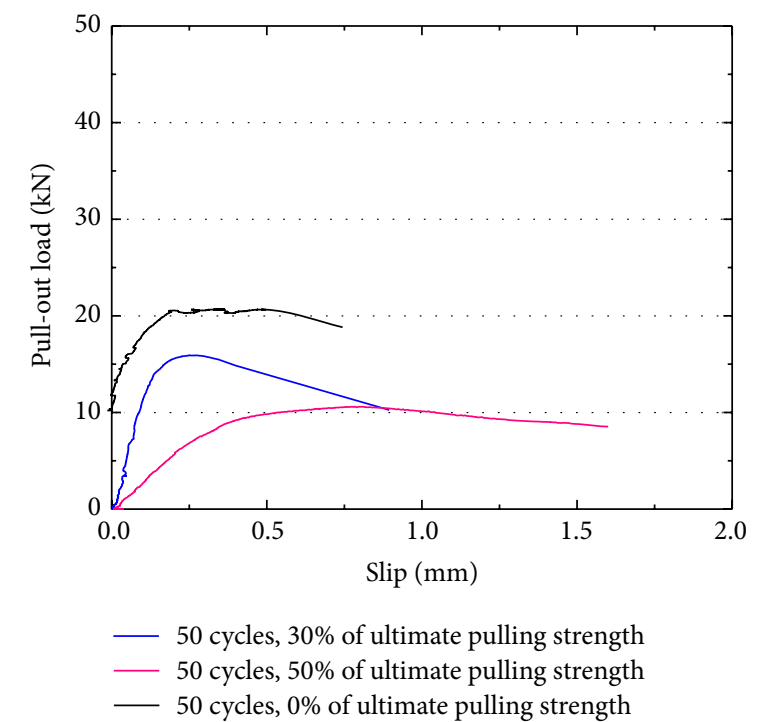

(c) Freeze-thaw cycles are 50 times and with applied sustaining load

FIGURE 9: Bond-slip curves for reinforced concrete suffering the coupling action of freeze-thaw damage and steel corrosion.

improve the resistance to steel corrosion under freezethaw environment. Steel corrosion in concrete can well be measured by the testing results of corrosion current density, and there exists a good correlation between the actual steel corrosion and testing results.

(2) Steel corrosion in air entrained concrete has a similar changing trend to that in ordinary concrete under freeze-thaw environment. However, attributing to the incorporation of air entrained agent, air entrained concrete has a good freeze-thaw resistance. Consequently, the steel corrosion rate in air entrained concrete is much lower than that in ordinary concrete. Even after high freeze-thaw cycles, steel is also in a low corrosion state. Furthermore, the actual degree of steel corrosion in air entrained concrete is also much lower than that in ordinary concrete. Air entrained concrete can reduce the rate and degree of steel corrosion under freeze-thaw environment.

(3) Because of the existence of hydrophobic coating formed on the surface of waterproofing concrete, the chloride content significantly reduces compared with that in ordinary concrete under the same freeze-thaw environment. Although frost damage increases the rate of steel corrosion in waterproofing concrete, the steel corrosion rate is obviously decreased compared with that in ordinary concrete, even after high freezethaw cycles are applied. Waterproofing concrete also 


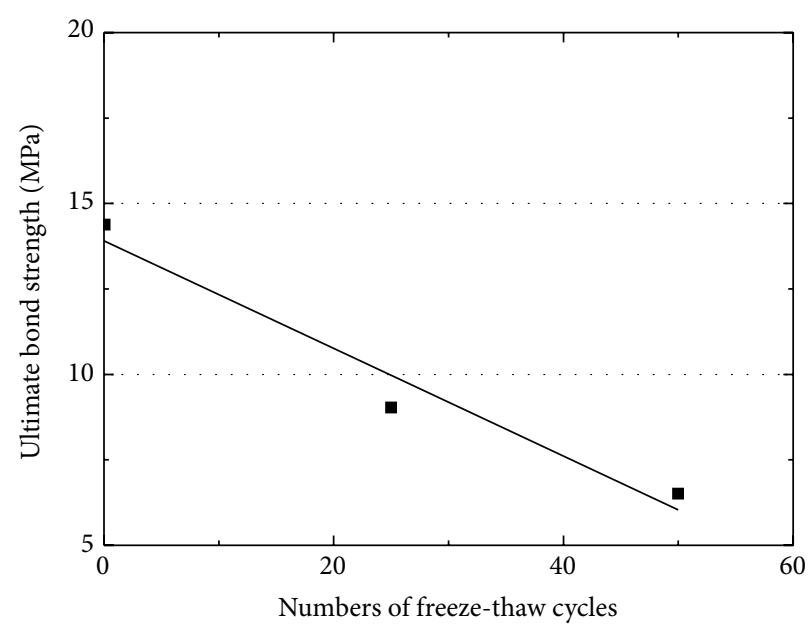

(a) Between the ultimate bond strength and freeze-thaw cycles

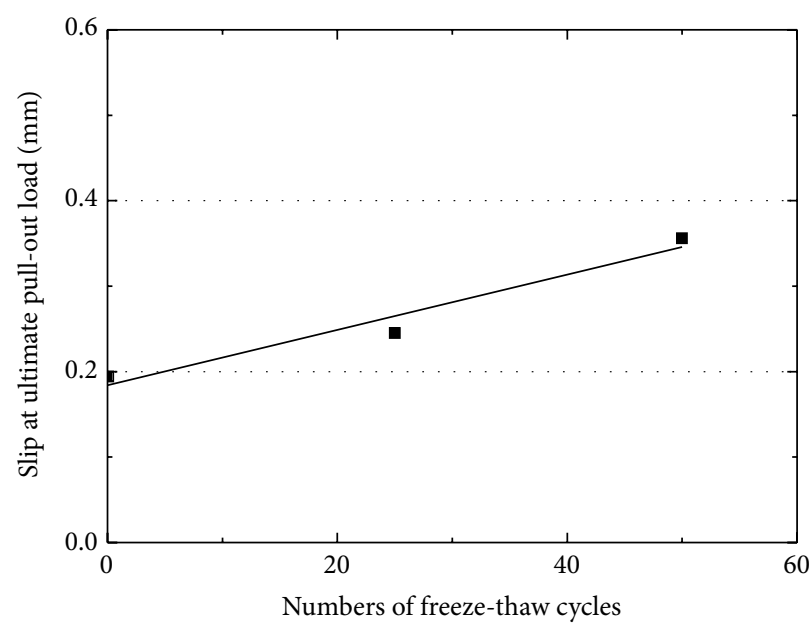

(b) Between the slip peak and freeze-thaw cycles

FIGURE 10: Relationship between the ultimate bond strength, slip peak, and freeze-thaw cycles.

possesses a better resistance to steel corrosion than ordinary concrete under freeze-thaw environment.

(4) The freeze-thaw damage has a significant impact on the bond-slip behavior of reinforced concrete with serious corrosion steel, and the ultimate bond-slip strength decreases with the increase of freeze-thaw cycles. In addition, there exists a good correlation between the bond-slip behavior and applied freezethaw cycles, which provides a method to evaluate the bond-slip behavior of reinforced concrete under freeze-thaw cycles, approximately.

\section{Competing Interests}

The authors declare that they have no competing interests.

\section{Acknowledgments}

The authors gratefully acknowledge substantial support of ongoing projects: Chinese National 973 Plan (2015CB655100) and Key International Cooperation Project (51420105015).

\section{References}

[1] B. Goszczyńska, G. Świt, W. Trampczyński, A. Krampikowska, J. Tworzewska, and P. Tworzewski, "Experimental validation of concrete crack identification and location with acoustic emission method," Archives of Civil and Mechanical Engineering, vol. 12, no. 1, pp. 23-28, 2012.

[2] E. Raue, H.-G. Timmler, and R. Garke, "On the physically non-linear analysis of cyclic loaded reinforced concrete crosssections with mathematical optimisation," Journal of Civil Engineering and Management, vol. 15, no. 2, pp. 189-195, 2009.

[3] R. P. Khatri and V. Sirivivatnanon, "Methods for the determination of water permeability of concrete," ACI Materials Journal, vol. 94, no. 3, pp. 257-261, 1997.

[4] Z. Ma, T. Zhao, and Y. Zhao, "Effects of hydrostatic pressure on chloride ion penetration into concrete," Magazine of Concrete Research, vol. 68, pp. 1-10, 2016.
[5] Z. Ma, T. Zhao, J. Xiao, and P. Wang, "Effect of applied loads on water and chloride penetrations of strain hardening cementbased composites," Journal of Materials in Civil Engineering, 2016.

[6] P. J. M. Monteiro and K. E. Kurtis, "Time to failure for concrete exposed to severe sulfate attack," Cement and Concrete Research, vol. 33, no. 7, pp. 987-993, 2003.

[7] M. Kosior-Kazberuk, "Variations in fracture energy of concrete subjected to cyclic freezing and thawing," Archives of Civil and Mechanical Engineering, vol. 13, no. 2, pp. 254-259, 2013.

[8] J. Šelih, "Performance of concrete exposed to freezing and thawing in different saline environments," Journal of Civil Engineering and Management, vol. 16, no. 2, pp. 306-311, 2010.

[9] C. Q. Li, J. J. Zheng, W. Lawanwisut, and R. E. Melchers, "Concrete delamination caused by steel reinforcement corrosion," Journal of Materials in Civil Engineering, vol. 19, no. 7, pp. 591600, 2007.

[10] B. Pradhan, "Corrosion behavior of steel reinforcement in concrete exposed to composite chloride-sulfate environment," Construction and Building Materials, vol. 72, pp. 398-410, 2014.

[11] Y.-S. Choi, J.-G. Kim, and K.-M. Lee, "Corrosion behavior of steel bar embedded in fly ash concrete," Corrosion Science, vol. 48, no. 7, pp. 1733-1745, 2006.

[12] T. D. Marcotte and C. M. Hansson, "Corrosion products that form on steel within cement paste," Materials and Structures, vol. 40, no. 3, pp. 325-340, 2007.

[13] Z. Li, F. Li, A. Zdunek, E. Landis, and S. P. Shah, "Application of acoustic emission technique to detection of rebar corrosion in concrete," ACI Materials Journal, vol. 95, no. 1, pp. 68-81, 1998.

[14] C. Andrade, C. Alonso, and F. J. Molina, "Cover cracking as a function of bar corrosion: Part I-experimental test," Materials and Structures, vol. 26, no. 8, pp. 453-464, 1993.

[15] Y. X. Zhao, J. Yu, B. Y. Hu, and W. L. Jin, "Crack shape and rust distribution in corrosion-induced cracking concrete," Corrosion Science, vol. 55, pp. 385-393, 2012.

[16] G. K. Glass and N. R. Buenfeld, "The presentation of the chloride threshold level for corrosion of steel in concrete," Corrosion Science, vol. 39, no. 5, pp. 1001-1013, 1997.

[17] C. G. Berrocal, K. Lundgren, and I. Löfgren, "Corrosion of steel bars embedded in fibre reinforced concrete under chloride 
attack: state of the art," Cement and Concrete Research, vol. 80, pp. 69-85, 2016.

[18] S. Coccia, S. Imperatore, and Z. Rinaldi, "Influence of corrosion on the bond strength of steel rebars in concrete," Materials and Structures, vol. 49, no. 1-2, pp. 537-551, 2016.

[19] M. Khanzadeh Moradllo, M. Shekarchi, and M. Hoseini, “Timedependent performance of concrete surface coatings in tidal zone of marine environment," Construction and Building Materials, vol. 30, pp. 198-205, 2012.

[20] W. Sun, R. Mu, X. Luo, and C. Miao, "Effect of chloride salt, freeze-thaw cycling and externally applied load on the performance of the concrete," Cement and Concrete Research, vol. 32, no. 12, pp. 1859-1864, 2002.

[21] L. C. Wang and J. Z. Wang, "Mesoscale simulation of chloride diffusion in concrete subjected to flexural loading," Advances in Structural Engineering, vol. 17, no. 4, pp. 561-572, 2014.

[22] L. Yu, R. François, V. H. Dang, V. L’Hostis, and R. Gagné, "Development of chloride-induced corrosion in pre-cracked RC beams under sustained loading: effect of load-induced cracks, concrete cover, and exposure conditions," Cement and Concrete Research, vol. 67, pp. 246-258, 2015.

[23] J. Z. Mao, Z. Y. Zhang, and Z. M. Liu, "Damage analysis of concrete subjected to freeze-thaw cycles and chloride ion erosion," Key Engineering Materials, vol. 488, pp. 464-467, 2012.

[24] Y. Xian, F. H. Wittmann, T. Zhao, and S. Giessler, "Chloride penetration into integral water repellent concrete/eindringen von chloriden in integral hydrophobierten beton," Restoration of Buildings and Monuments, vol. 3, pp. 17-24, 2007.

[25] D. U. Ai-Ling, H. O. U. Wen-Tao, Z. He-Ming, and L. Jian-Qun, "The lineal polarization method for corrosion rate measurement of reinforcing bar of concrete in situ," Electrochemistry, vol. 6, pp. 297-304, 2000.

[26] Y. Zhao, J. Dong, Y. Wu, H. Wang, X. Li, and Q. Xu, "Steel corrosion and corrosion-induced cracking in recycled aggregate concrete," Corrosion Science, vol. 85, pp. 241-250, 2014.

[27] S. G. Millard, D. Law, J. H. Bungey, and J. Cairns, "Environmental influences on linear polarisation corrosion rate measurement in reinforced concrete," NDT \& E International, vol. 34, no. 6, pp. 409-417, 2001.

[28] S. Li, G. Chen, G. Ji, and Y. Lu, "Quantitative damage evaluation of concrete suffered freezing-thawing by DIP technique," Construction and Building Materials, vol. 69, pp. 177-185, 2014.

[29] L. Wang and T. Ueda, "Mesoscale modeling of chloride penetration in unsaturated concrete damaged by Freeze-Thaw cycling," Journal of Materials in Civil Engineering, vol. 26, no. 5, pp. 955965, 2014.

[30] Z. Wang, Q. Zeng, L. Wang, Y. Yao, and K. Li, "Corrosion of rebar in concrete under cyclic freeze-thaw and Chloride salt action," Construction and Building Materials, vol. 53, pp. 40-47, 2014.

[31] J. Li, X. Peng, and Z. Deng, "Quantitative design on the frostresistance of concrete," Concrete, vol. 134, pp. 61-65, 2000 (Chinese). 

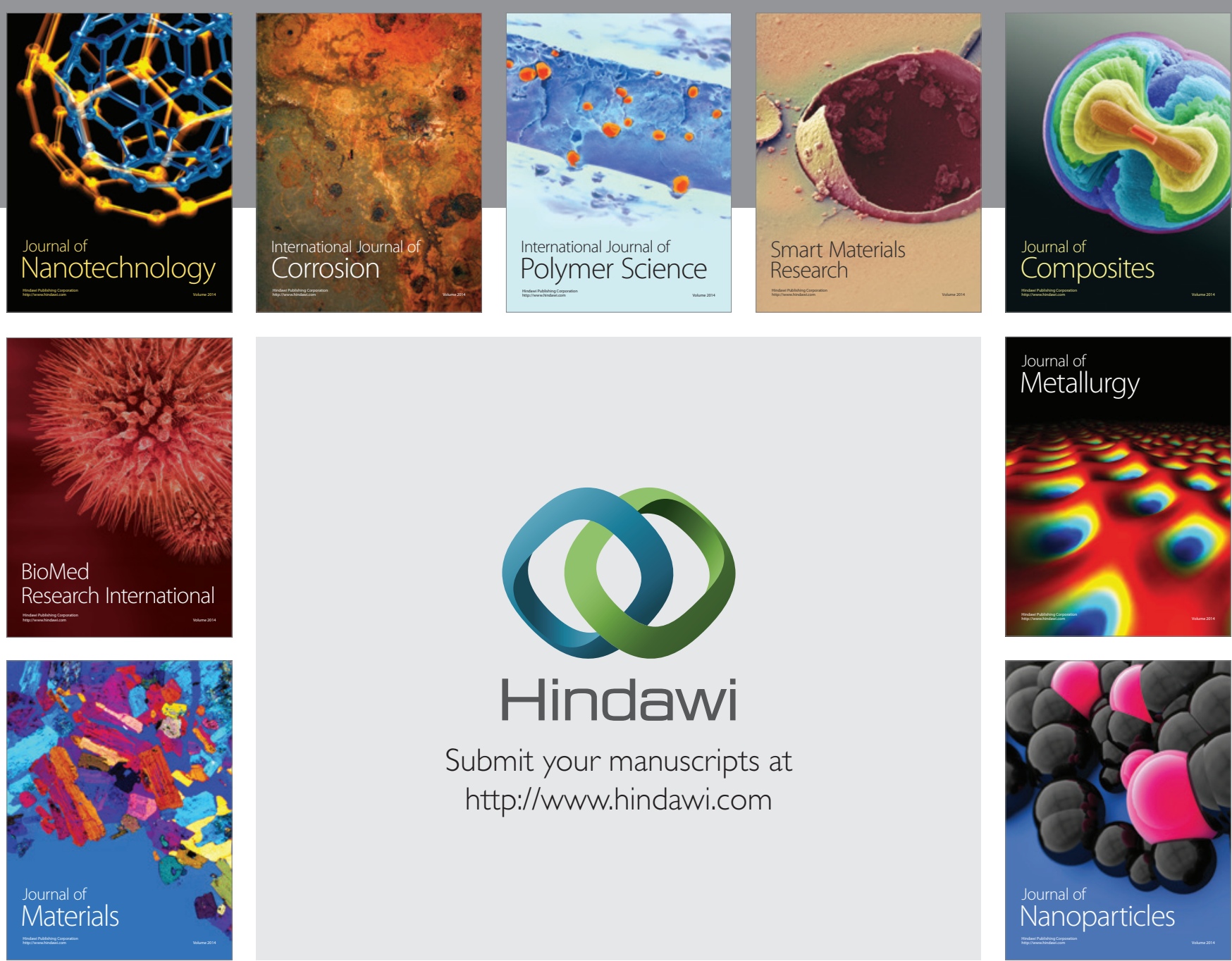

\section{Hindawi}

Submit your manuscripts at

http://www.hindawi.com

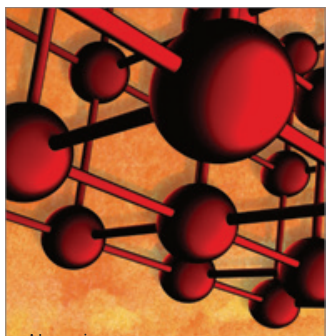

Materials Science and Engineering
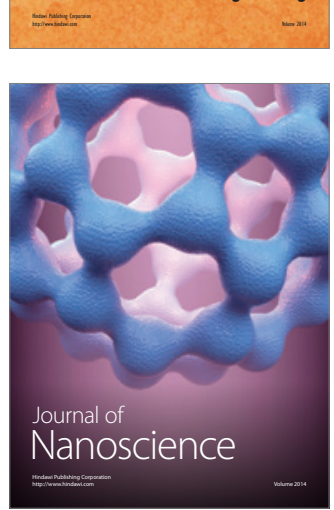
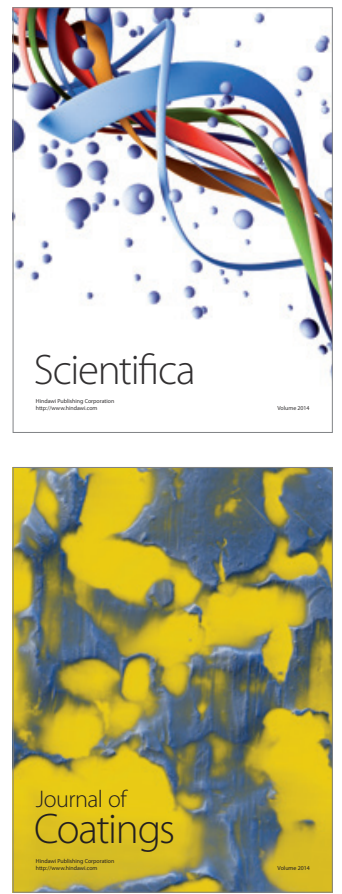
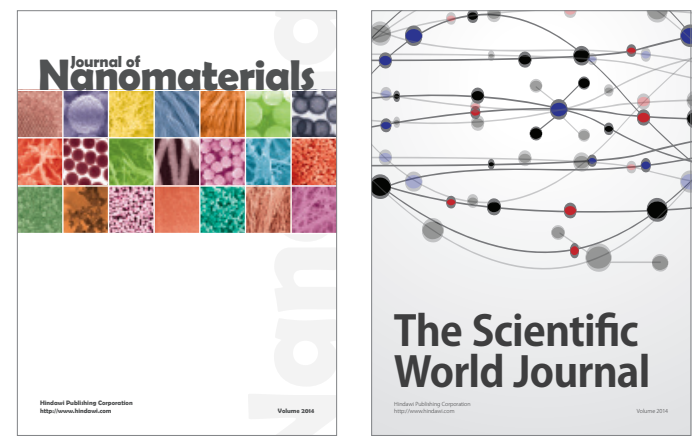

The Scientific World Journal
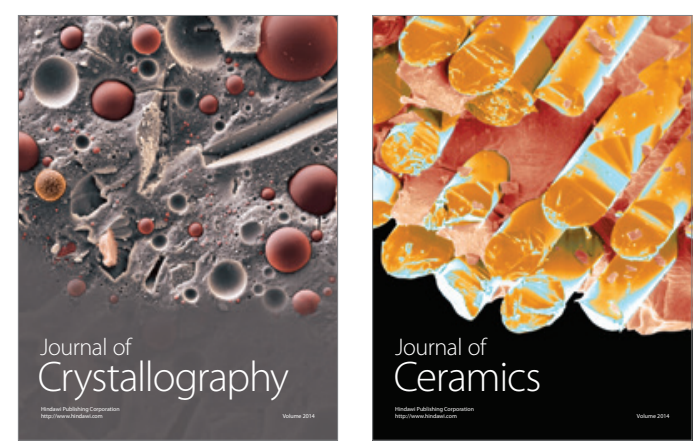
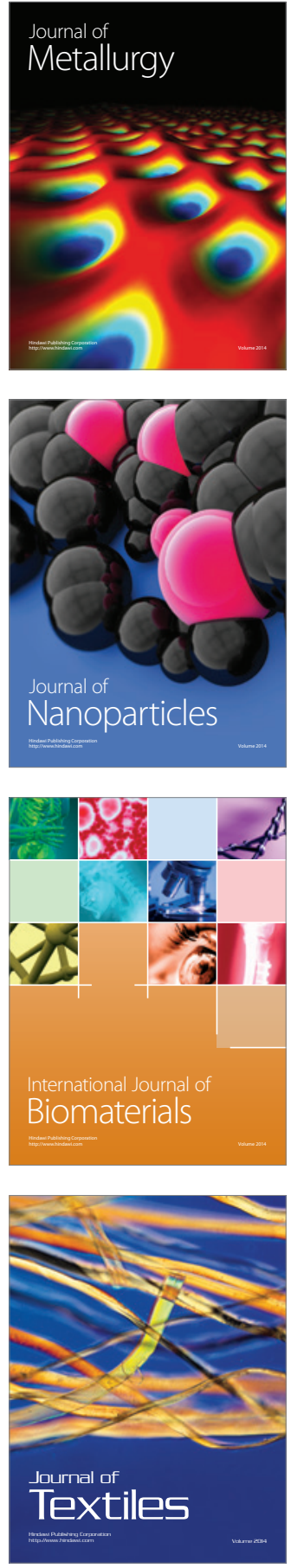